\title{
Personality, Sex and Systemic Inflammation
}

\author{
Leah FitzGerald ${ }^{*}$, Paul M. Macey ${ }^{1}$, Mary-Lynn Brecht ${ }^{1,2}$ \\ ${ }^{1}$ University of California, Los Angeles-School of Nursing, Los Angeles, USA \\ ${ }^{2}$ University of California, Los Angeles-School of Medicine, Semel Institute, Integrated Substance Abuse \\ Programs, Los Angeles, USA \\ Email: Ifitzger@sonnet.ucla.edu
}

Received 25 April 2014; revised 21 May 2014; accepted 15 June 2014

Copyright (C) 2014 by authors and Scientific Research Publishing Inc.

This work is licensed under the Creative Commons Attribution International License (CC BY). http://creativecommons.org/licenses/by/4.0/

(c) (i) Open Access

\section{Abstract}

Objective: Certain personality traits have been associated with increased risk of chronic systemic inflammation. Since the expression of personality traits differs by sex, this factor may also influence the associations between personality and inflammation. The objective of this study was to investigate the association between the five dimensions of personality and high-sensitivity interleukin-6 (IL6) in a healthy population, and to determine whether these relationships were different in men and women. Methods: IL6 was measured in 91 medically healthy participants, and per-sonality was assessed using the Five-Factor Model (FFM) of personality. Physical activity was also measured using the International Physical Activity Questionnaire (IPAQ), since physical activity is known to influence inflammation. Multivariable regression models were estimated for each sex, including personality domains and level of physical activity, controlling for age and body mass index (BMI). Results: Higher ratings in the dimension of Openness to Experience predicted higherIL6 values in men only, after adjusting for age and BMI, variables known to affect inflammation $(p<0.05)$. Similarly in women only, higher Agreeableness predicted lower IL6 levels. Level of physical activity did not predict IL6 in either sex. Conclusion: Relationships between IL6 and personality traits exist in both men and women, but the nature of these associations differs by sex. These associations appear to be independent of other factors including physical activity. The findings raise the possibility that certain personality domains may make people more vulnerable to, or more protected from, conditions usually associated with pathological, chronic systemic inflammation.

\section{Keywords}

Behavioral Immunology, Personality, Openness, Agreeableness, Interleukin-6, Sex

\footnotetext{
${ }^{*}$ Corresponding author.
} 


\section{Background}

The relationship between personality and inflammation is an area of inquiry that can contribute to understanding mechanisms underlying the continuum of health and illness (Segerstrom, Taylor, Kemeny, \& Fahey, 1998). Personality may affect inflammation indirectly through the different behavior of individuals with different personality factors. The Five-Factor Model (FFM) of personality provides a framework to examine personality and health, and is categorized into five broad domains: Neuroticism, Extraversion, Openness to Experience, Agreeableness, and Conscientiousness (Widiger \& Costa, 2012) and is a well-established framework for studying links between personality and levels of inflammation.

Personality is associated with variation in biological responses, but the extent to which it may be associated with inflammation, a pathophysiological state that is a precursor to many disease states, is unclear. Health behaviors that vary by personality are associated with inflammation (Chapman et al., 2011). In addition, certain personality factors are associated with variations in physical activity, which is beneficial to overall health, in part due to physiological changes that lower risk factors for cardiovascular disease, including reduced inflammation. The health behavior model of personality suggests certain personality traits are associated with engagement in that adjusting for BODY MASS INDEX and other health behaviors decreases the personality-inflammation link (Chapman et al., 2011) or health debilitating behaviors (Suls, Krantz, \& Williams, 2013), which are in turn, associated with higher levels of inflammation (Colbert et al., 2004; Mõttus, Luciano, Starr, Pollard, \& Deary, 2013). For example, attributed in part to poor health habits, individuals high on Neuroticism and low on Conscientiousness are vulnerable to poor health outcomes and increased mortality (Goodwin \& Friedman, 2006; Terracciano, Lockenhoff, Crum, Bienvenu, \& Costa, 2008). Low scores on Agreeableness have been associated with significantly lower perceived confidence and ability to manage chronic illness (Cheung, 2014). Additional FFM correlates of higher levels of inflammation include low openness to experience for Interleukin 6 (IL6) longitudinally (Chapman et al., 2011) and Jonassaint (Jonassaint, 2010) reported higher levels of Openness to Experience were associated with lower levels of inflammatory markers in African Americans. Individuals who score high on Openness to Experience are generally described as those with unconventional values, more likely to entertain novel ideas and experience both intense positive and negative emotions (Jonassaint et al., 2007). Alternatively, low scorers are described as more conservative, retaining conventional values and outlooks and comparatively experience a narrow range of emotional responses. High Neuroticism has been associated with high IL6 levels and associated with poor health habits in persons with low Conscientiousness (Sutin et al., 2010).

Alternatively, an individual with high levels of Conscientiousness may have lower levels of circulating inflammation due to the beneficial health behaviors and negatively associated with health-risk behaviors (Sutin et al., 2010). Further, individuals high in both Conscientiousness and Neuroticism had lower circulating IL-6 levels that were suggested to be impacted by health behaviors and obesity (Turiano, Mroczek, Moynihan, \& Chapman, 2013).

Personality characteristics associated with chronic inflammation as measured by circulating IL6 include negative personality states such as depression, hostility and anger. Since personality is a trait characteristic, the negative states may therefore be mechanisms leading to chronic elevated inflammation in some people (Halaris et al., 2012). Alternatively, faster immune recovery from stress is associated with positive affect (Segerstrom et al., 1998). Sex is another factor that may interact with personality to produce different immune system influences in men and women. Sex hormones play a role cytokines differences between in men and women (Ma et al., 2007) and that while the female hypothalamus tends to be more stress-sensitive, we still cannot determine the cause (Putnam, Chrousos, Nieman, \& Rubinow, 2005).

In addition, positive affective states have shown differential neuroendocrine-inflammatory associations in men and women, suggesting that, for women, a "happier" state of mind is related to reduced levels of inflammatory markers (Steptoe \& Molloy, 2007). Another sex-specific finding is that highly-sociable gay men infected with human immunodeficiency virus (HIV) had slower CD4 T cell decline, higher viral load, and higher response to highly active antiretroviral therapy compared to less social HIV-infected gay men (Cole, Kemeny, Fahey, Zack, \& Naliboff, 2003). Identifying relationships between specific behavioral trait of sociability and immune function/disease progression allows further insight into mechanisms underlying the previously-established relationships between human personality and disease resistance or susceptibility.

IL6 is an important family of mediators involved in the regulation of the acute-phase response to injury and 
infection, and inflammation that stimulates the Hypothalamic-Pituitary-Adrenal Axis (HPA) and the sympathetic nervous system (FitzGerald, 2011). Physical activity results in acute elevation of inflammatory markers, but long-term, physical activity is associated with lower levels of systemic inflammation (Nimmo, Leggate, Viana, \& King, 2013). IL6 is a key mediator in the activation of the HPA axis during physical activity, as shown by the exercise-induced increase of endogenous IL6 in normal subjects leads to stimulation of the HPA axis. However, chronic elevation of inflammatory markers is a risk factor for several disease states (Kim, West, \& Byzova, 2013), and is an independent predictor of cardiovascular mortality among seemingly healthy adults (Empana et al., 2010).

To this end, our objective was to assess the independent association of personality dimensions with inflammation, while also considering the influence of sex and physical activity. More specifically, we examined whether FFM personality factors and self-reported physical activity were associated with plasma IL6 levels for men and for women, controlling for age and BMI. We hypothesized that high Neuroticism and high Conscientiousness as well as high physical activity would be associated with plasma IL6; but relationships may differ in men and women, since studies have shown that women have higher circulating levels of IL6.

\section{Methods}

\subsection{Participants}

Ninety-one participants were recruited from the greater Los Angeles, California area through flyers and advertisements in a local paper. The sample was composed of 48 men and 43 women. Participants ranged in age from 18 - 50 years.

\subsection{Measurements and Protocol}

All participants underwent an eligibility screening and physical examination by a nurse practitioner. Candidates were free from co-morbid conditions affecting inflammatory markers and any known cardiovascular, respiratory or metabolic disorders. Participants did not take any medications, including over-the-counter pain/anti-inflammatory medication and were non-smokers. Written consent was obtained prior to the investigation which was approved by the University of California Los Angeles Institutional Review Board for use of human subjects, in accordance with the Helsinki declaration. Following eligibility screening, information regarding demographic characteristics, physical activity and depression were collected. Height $(\mathrm{cm})$ and body weight $(\mathrm{kg})$ were measured to the nearest $0.25 \mathrm{~cm}$ and nearest $0.1 \mathrm{~kg}$, respectively, using a floor model physician's scale/stadiometer; body mass index was calculated (BMI: $\mathrm{kg} \cdot \mathrm{m}^{2}$ ).

\subsection{Measurement of Psychosocial Parameters}

\subsubsection{NE0-Five Factor Inventory (FFI)}

A validated self-report version of the 60-item FFI was administered, yielding dimension scores for Neuroticism, Extroversion, Openness, Agreeableness and Conscientiousness (Costa Jr. \& McCrae, 1997). Item responses involve a 5-point Likert scale ranging from 0 ("Strongly Disagree”) to 4 ("Strongly Agree”). Each factor captures a wide array of behaviors. Openness reflects a preference for novelty and variety, which may be manifested as intellectual curiosity and interests. People high on Conscientiousness are typically described as organized, disciplined, and oriented towards achievement. Extroverted people show a high degree of sociability, talkativeness, warmth, and assertiveness. People high on agreeableness are likely to be helpful, sympathetic, and cooperative towards others. Lastly, Neuroticism captures dimensions of emotional negativity, stability, anxiety, vulnerability, and impulse control.

\subsubsection{International Physical Assessment Questionnaire (IPAQ)}

Physical activity was measured with a detailed questionnaire that quantified activity as a number of metabolic equivalent tasks (MET's) per week, with IPAQ. IPAQ estimates weekly time spent in different dimensions of physical activity and of physical inactivity. Total physical activity level was calculated and recorded in METminutes per week (MET-min/wk) according to the IPAQ scoring protocol (www.ipaq.ki.se). IPAQ responses were converted into metabolic equivalents (METS) and participants were categorized into "low", "moderate" or "vigorous” activity levels based on standard IPAQ scoring cutoffs and guidelines (Craig et al., 2003), with MET 
values of $8.0,4.0$ and $3.3 \mathrm{~min} / \mathrm{wk}$ corresponding to cut-offs for vigorous-intensity, moderate-intensity, and walking activities, respectively. For the regression analysis, the activity level was considered an ordinal variable with values 1 = low, 2 = moderate, 3 = vigorous.

\subsubsection{Beck Depression Inventory (BDI)}

To screen for possible depression, participants completed the Beck Depression Inventory (BDI) (Beck, Ward, Mendelson, Mock, \& Erbaugh, 1961), one of the most widely used measures of the severity of depression in diagnosed patients and for detecting possible depression in normal populations (Beck et al., 1961). The screening procedure produced a sample with depression scores in the normal range, with little variability.

\subsection{Measurement of Immune Parameter}

\section{IL6 Assay}

Participants were fasting (except for water) for 8 hours and free of vigorous physical activity for a minimum of 24 hours prior to sampling. They sat quietly for 10 minutes prior to blood draw. Single $20 \mathrm{ml}$ blood samples were collected between 10 am and 2 pm. Blood sample to measure plasma IL-6 was collected in tubes containing ethylenediaminetetraacetic acid. Within 1 hour of collection, blood samples were centrifuged at $4^{\circ} \mathrm{C}$ at 3000 $\mathrm{g}$ for $20 \mathrm{~min}$, and the plasma was harvested, and stored in polypropylene tubes at $-80^{\circ} \mathrm{C}$ until analyses. Levels of IL6 were determined using a high-sensitivity enzyme-linked immunosorbent assay (Quantikine HS; R \& D Systems, Minneapolis, MN) that has a mean minimum detectable dose range of $0.016-0.011 \mathrm{pg} / \mathrm{ml}$. Randomly selected samples were assayed in duplicate to monitor within plate and plate-to-plate variability. Coefficients of variations were less than $10 \%$.

\subsection{Statistical Analysis}

Preliminary analysis considered simple bivariate correlations between predictors (personality dimensions and level of physical activity with IL6, and for covariates age and BMI) for males and for females. The inflammatory marker IL6 (logIL-6) was log-transformed for analysis because of skewed distribution. Partial correlations of logIL-6 with personality dimensions and level of physical activity, controlling for BMI and age, were also computed for each sex and for the total sample. Because correlations and partial correlations suggested differences between males and females on some dimensions, further preliminary analyses explored sex by personality dimension interactions, one dimension at a time, using regression analysis on the full sample $(n=91)$. For these preliminary models, logIL-6 was the dependent variable with sex, one dimension score, and the sex-by-dimension interaction entered as independent variables; dimension scores were centered at zero and sex used unweighted effects coding. Because two of the dimensions Agreeableness and Openness, showed significant (at $p<0.05$ ) interaction effects (and Conscientiousness $p=0.16$ ), further multivariable regression analyses (presented in this paper and explained in more detail below) were implemented separately on males and females.

The primary analysis estimated regression models to examine the relationship of logIL-6 to the personality predictors independent of level of physical activity and controlling for age and BMI; separate models were estimated for males and females. Because samples were relatively small ( $n=43$ for females, $n=48$ for males) and there was some correlation among personality dimensions, for parsimony, reduced models were also estimated for each sex, including physical activity level and only those sex-specific personality dimensions with $p<=0.10$ (and controlling for age and BMI). In addition to regression coefficients, standardized beta coefficients were presented to allow comparisons of magnitude of association effects across predictor variables.

\section{Results}

\subsection{Description}

A majority (45\%) of the sample was (Caucasian), with representation of other major racial/ethnic groups (Table 1). The average participant was 35.09 (11.13) years. Female age was $28.79 \pm 9.01$ years and the average age of males was $35.09 \pm 11.13$ years. The mean FFI scores of the study population were comparable with the mean ranges of the normative population (Costa Jr. \& McCrae, 1997). Table 2 shows for each sex simple bivariate correlations among personality dimensions, physical activity level, and covariates of age and BMI. 
Table 1. Descriptive statistics: Sample demographics, logIL-6, and predictors from regression model.

\begin{tabular}{|c|c|c|c|}
\hline & Total Sample $\quad n=91$ & Females $n=43$ & Males $\mathrm{n}=48$ \\
\hline & & Mean (SD) or n (\%) & Mean (SD) or $n(\%)$ \\
\hline \multicolumn{4}{|l|}{ SEX } \\
\hline Male & 48 (53\%) & & \\
\hline Female & $43(47 \%)$ & & \\
\hline \multicolumn{4}{|l|}{ RACE/ETHNICITY } \\
\hline Black & 17 (19\%) & $9(21 \%)$ & $8(17 \%)$ \\
\hline White (non-Hispanic) & 41 (45\%) & $17(40 \%)$ & $24(50 \%)$ \\
\hline Asian/Pacific Isl. & $15(16 \%)$ & $8(19 \%)$ & $7(15 \%)$ \\
\hline Hispanic & $16(18 \%)$ & $8(19 \%)$ & $8(17 \%)$ \\
\hline Other & $2(2 \%)$ & $1(2 \%)$ & $1(2 \%)$ \\
\hline AGE years (SD) & $32.11(10.64)$ & $28.79(9.08)$ & 35.09 (11.13) \\
\hline BMI $^{*}$ & $24.73(4.16)$ & $23.63(3.32)$ & $25.71(4.60)$ \\
\hline \multicolumn{4}{|c|}{ PHYSICALACTIVITY GROUP } \\
\hline Low & $42(46 \%)$ & $26(60 \%)$ & $16(33 \%)$ \\
\hline Moderate & 37 (41\%) & $13(30 \%)$ & $24(50 \%)$ \\
\hline High & $12(13 \%)$ & $4(9 \%)$ & $8(17 \%)$ \\
\hline A & 47.35 (6.08) & $49.35(5.26)$ & $45.56(6.25)$ \\
\hline $\mathrm{C}$ & 47.99 (7.93) & $48.53(9.24)$ & $47.50(6.61)$ \\
\hline $\mathrm{E}$ & $43.31(8.15)$ & $43.74(8.43)$ & $42.92(7.97)$ \\
\hline $\mathrm{N}$ & $29.04(5.81)$ & $29.81(5.61)$ & 28.35 (5.95) \\
\hline $\mathrm{O}$ & 77.15 (18.43) & $87.26(7.94)$ & $68.10(20.42)$ \\
\hline $\log I L-6$ & $0.55(1.16)$ & $1.42(0.88)$ & $-0.23(0.76)$ \\
\hline
\end{tabular}

"kg $\cdot \mathrm{m}^{2}$; A: Agreeableness; C: Conscientiousness; E: Extraversion; N: Neuroticism; O: Openness to Experience.

Table 2. Bivariate Correlations between predictors considered.

\begin{tabular}{|c|c|c|c|c|c|c|c|c|c|c|c|c|c|c|}
\hline & \multicolumn{7}{|c|}{ Females } & \multicolumn{7}{|c|}{ Males } \\
\hline & age & BMI & A & $\mathrm{C}$ & E & $\mathrm{N}$ & $\mathrm{O}$ & age & BMI & A & $\mathrm{C}$ & E & $\mathrm{N}$ & $\mathrm{O}$ \\
\hline BMI & 0.15 & & & & & & & 0.14 & & & & & & \\
\hline A & 0.14 & -0.19 & & & & & & 0.10 & 0.18 & & & & & \\
\hline $\mathrm{C}$ & 0.04 & 0.08 & $0.42^{*}$ & & & & & 0.16 & 0.07 & 0.18 & & & & \\
\hline $\mathrm{E}$ & -0.16 & -0.09 & 0.22 & $0.45^{*}$ & & & & $0.29^{*}$ & -0.04 & 0.13 & $0.42^{*}$ & & & \\
\hline $\mathrm{N}$ & -0.03 & 0.18 & $-0.53^{*}$ & -0.22 & -0.22 & & & 0.03 & 0.19 & $-0.34^{*}$ & $-0.31^{*}$ & $-0.42^{*}$ & & \\
\hline $\mathrm{O}$ & 0.00 & -0.28 & $0.81^{*}$ & $0.32^{*}$ & $0.33^{*}$ & $-0.37^{*}$ & & -0.27 & 0.20 & 0.18 & -0.25 & -0.04 & 0.05 & \\
\hline phactgr $^{*}$ & -0.19 & -0.15 & 0.24 & 0.22 & 0.13 & $-0.36^{*}$ & 0.22 & 0.05 & 0.03 & -0.07 & $0.34^{*}$ & $0.29^{*}$ & -0.12 & -0.16 \\
\hline
\end{tabular}

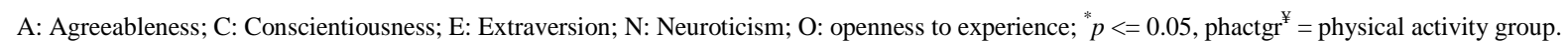

\subsection{Associations between LogIL-6 and Personality Scores}

Total sample: As shown in Section I of Table 3, partial correlations (controlling for age and BMI) showed that plasma logIL-6 level was significantly associated with Neuroticism $(r=0.25)$ and with Openness to Experience $(r=0.47)$ in the total sample. Moreover, there was a significant relationship between logIL-6 concentrations and level of physical activity $(r=-0.36)$, with lower logIL-6levels corresponding to higher levels of physical activity. No other markers of inflammation (e.g. TNF- $\alpha$, IL-1 $\beta$ ) were assessed. Females: Plasma logIL-6 level was sig- 
Table 3. Partial correlations and regression estimates for logIL-6 with personality dimensions and level of physical activity, controlling for age and BMI.

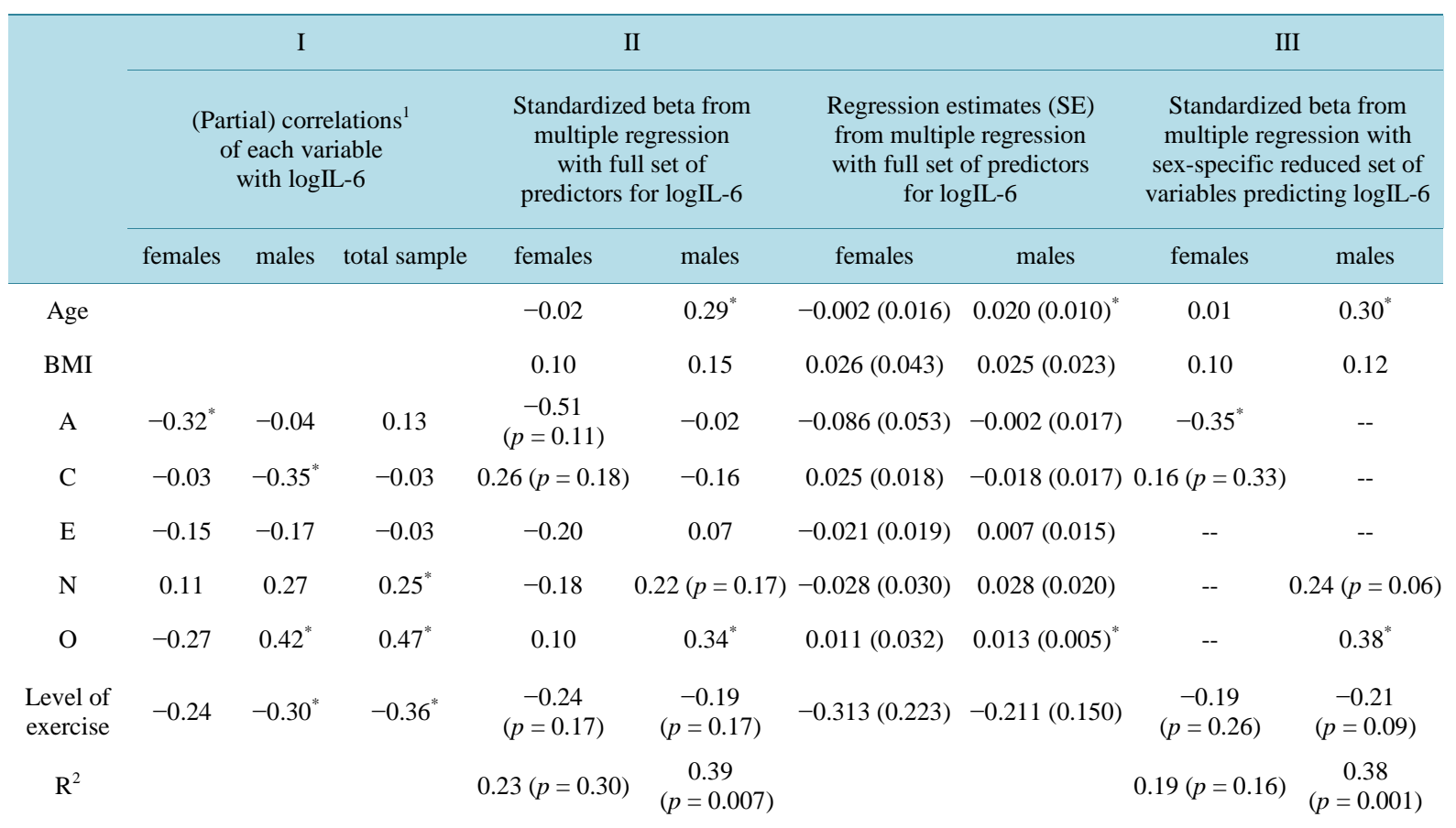

${ }^{*} p<=.05 ;{ }^{1}$ Controlling for Age and BMI; I. partial correlations of each predictor or covariate with logIL-6, controlling for age and BMI. II. The "full model" with 6 primary predictors (level of physical activity and the personality dimensions) and 2 covariates (age and BMI). III. Parsimonious models for each sex, omitting predictors with $p>0.20$ in full model. These are sex-specific reduced models; that is, different variables have been omitted depending on results of the sex-specific full models.

nificantly associated with Agreeableness $(r=-0.32)$ as shown by partial correlations, with lower logIL-6 levels corresponding to higher ratings of Agreeableness.

Males: Plasma logIL-6 levels were significantly associated with Conscientiousness $(r=-0.35)$, Openness to Experience $(r=0.42)$ and Level of Physical activity $(r=-0.30)$, with lower logIL-6 levels corresponding to higher ratings of Conscientiousness and Level of Physical activity and lower ratings of Openness to Experience. The reduced regression model for males (see Section III of Table 3) was significant $\left(p=0.001, \mathrm{R}^{2}=0.38\right.$ ) but not for females $\left(\mathrm{R}^{2}=0.19, p=0.16\right)$. Note that there was little loss of explained variance by omitting some predictors from the full regression models (Section II of Table 3) to create the reduced models. Primary predictors remained consistent in direction of relationship and were relatively similar in magnitude across partial correlations, full regression model, and reduced model within sex categories. But the sexes differed in magnitude and/or direction of relationships for the personality dimensions. For example, for females, higher agreeableness scores were independently associated with lower logIL-6 levels at moderate levels (beta $=-0.35$, partial $\mathrm{R}^{2}=$ 0.099), controlling for level of physical activity, other personality dimensions in the model, and covariates of age and BMI; but this personality dimension was not significant for males. On the other hand, Openness to Experience was significantly related to logIL-6 levels in men (beta $=0.38$, partial $\mathrm{R}^{2}=0.166$ ), but not in females.

For both sexes, level of physical activity was negatively (but not statistically significantly) related to logIL-6 in the regression models, independent of personality dimensions and controlling for age and BMI, whereas physical activity level was significant for males in partial correlations when personality dimensions were not considered. The standardized beta coefficients and partial $\mathrm{R}^{2}$, indicating relative magnitude of association across predictors in the models suggest that in this sample, sex-specific personality dimensions more strongly predicted logIL-6 levels than did level of physical activity.

Note also that among females, there was a strong correlation between dimensions of Agreeableness and Openness to Experience $(r=0.41)$, but the latter dropped from significance in the full regression model; substituting Openness for Agreeableness in the reduced model resulted in a slightly less predictive model $\left(p=0.06, \mathrm{R}^{2}\right.$ 
= 0.13), and showed a relationship between Openness and logIL-6 opposite in direction than that for males.

\section{Discussion}

For more than sixty years, personality has been known to influence both positive and negative health outcomes (Segerstrom et al., 1998; Steptoe \& Molloy, 2007; Temoshok, Wald, Synowski, \& Garzino-Demo, 2008). Certain personality traits have been associated with increased risk of chronic systemic inflammation. We examined whether the Big 5 personality dimensions were associated with IL6 in healthy males and females, and the extent to which physical activity and sex might explain this association. Our findings were that personality phenotype had a greater impact on systemic inflammation than physical activity, and the impact differed between men and women according to different personality characteristics. Controlling for age and BMI, higher scores of Openness have more of an impact on IL6 than physical activity among males than females and lower scores of Agreeableness have more of an impact on IL6 than physical activity among females than males. The finding of a weaker influence of physical activity on inflammation was surprising, but reinforces the importance of personality with regards to potentially harmful immune system activity.

Various explanations have been reported to account for the associations between personality and inflammation. One possible pathway between personality and inflammation involves the psychophysiology of stress. It has been suggested that a possible index of HPA activation can be reflected in personality phenotype in individuals who self-select into stressful situations, demonstrate variation in stress perception and coping (de Jong, van Sonderen, \& Emmelkamp, 1999; Roberts, Caspi, \& Moffitt, 2001). Inconsistent with our findings, others have reported (favorable) associations between inflammatory markers and Openness to Experience.

Higher Openness to Experiencepredicted lower IL6 levels in older community sample after adjusting for common health behaviors and health conditions (Chapman, Fiscella, Kawachi, \& Duberstein, 2010) and lower CRP was associated with higher Openness to Experience among middle aged blacks (Jonassaint, 2010). Longitudinal research into individual facets of Openness to Experience in patients with cardiac disease has shown physiological and biological underpinnings of the links between greater emotional awareness and high curiosity, and increased longevity (Jonassaint et al., 2007). However, these studies did not control for sex, which the present findings suggest could modify the relationships discovered in the earlier work. Higher Openness to experience may be sex specific, as our findings demonstrate a less favorable impact on IL6 among males in our study population.

Our findings of lower IL6 levels in persons with higher ratings on Agreeableness are consistent with previous findings (Sutin et al., 2010). The observed magnitude in our population is greater than reported in the literature. That IL6 levels were significantly different between males and females may suggest that sex may affect changes in a range of inflammatory markers (Edwards, Burns, Ring, \& Carroll, 2006b) and that the Agreeableness personality phenotype may be less helpful in males.

An alternative pathway between personality and inflammation involves direct or indirect impact inflammatory health behavior leading to a direct inflammatory response or indirectly via the cost of illness (Chapman et al., 2011). Our findings did not support our hypothesis that physical activity would explain the relationship between personality and IL6. None of the health behaviors that were examined accounted for the association between personality and IL6 (physical activity, BMI). We observed a significant correlation between level of physical activity and IL6 in the total sample and in the males. In addition, there was a trend toward significance for males in the regression analysis, which conforms to the notion that physical activity affects plasma cytokine levels in an intensity and sex dependent manner (Dressendorfer et al., 2002; Edwards, Burns, Ring, \& Carroll, 2006a). A considerable literature documents the effects of long-term physical activity on health (Jankord \& Jemiolo, 2004). Moderate physical activity is associated with enhanced cardiovascular and metabolic function and reduced body fat (Jankord \& Jemiolo, 2004). Lifestyles associated with high-intensity and high-volume physical activity result in positive changes in chronic low-grade inflammatory markers (Lira et al., 2010). While physical activity was not a significant factor in the present study, other personality-influenced behaviors (e.g., diet, stress reduction practices) may lead to lower inflammatory levels.

\section{Limitations}

Strengths of the present study include use of validated measures of physical activity assessment using calculated metabolic equivalents and the use of both medical exam format and self-report to gather information on lifestyle. 
In addition, looking at sex specific responses to IL6 in relation to personality phenotype adds to the literature. However, the study results should be considered within the constraints of several limitations. The cross-sectional design does not allow us to make any causal inferences of the sex-differential influence of personality independent from level of physical activity on systemic inflammation. Thus the mechanism of influence could not be examined; future research could examine whether level of physical activity mediates or moderates relationships of personality dimensions with inflammation. There are mechanisms that were not measured in this study may underpin associations between personality and systemic inflammation. While single measurements of plasma IL6 among healthy individuals have been shown to provide a good estimate of long-term levels (Chapman et al., 2011), the generalizability of findings could be enhanced by future replication with additional inflammatory measurements. The generalizability of study findings are limited by the small healthy sample. The relatively small sample size for each sex somewhat limits power for detecting significant results; the sample size, however, should have been adequate for detecting medium effects of about $\mathrm{f}^{2}=0.20$ with power $=0.80$ and alpha $=0.05$.

\section{Conclusion}

The present data indicate that sex-specific personality dimensions appear to more strongly predict IL6 levels than does the level of physical activity. Our findings propose sex as a potential modifier by which personality increases risk for inflammatory disease. Further insight that identifies underlying mechanisms may lead to individualized treatment tailored to the personality and coping styles, as well as sex, of the individual patient. Future validation of these findings may lead to primary care providers screening and identifying at risk personality phenotypes and offering interventions to reduce the negative health consequences of systemic inflammation.

\section{Conflicts of Interest and Source of Funding}

No conflicts of interest are declared. Funding support for this work was provided by Sigma Theta Tau, Gamma Tau at Large Chapter and the Cousins Center for Psychoneuroimmunology at the UCLA Semel Institute for Neuroscience.

\section{Contributors}

Author FitzGerald designed the study, wrote the protocol and managed the literature searches and analyses. Author Brecht undertook the statistical analysis, and author Macey provided assistance with study design. All authors contributed to and have approved the final manuscript.

\section{References}

Beck, A. T., Ward, C. H., Mendelson, M. M., Mock, J. J., \& Erbaugh, J. J. (1961). AN Inventory for Measuring Depression. Archives of General Psychiatry, 4, 561-571. http://dx.doi.org/10.1001/archpsyc.1961.01710120031004

Chapman, B. P., Fiscella, K., Kawachi, I., \& Duberstein, P. R. (2010). Personality, Socioeconomic Status, and All-Cause Mortality in the United States. American Journal of Epidemiology, 171, 83-92. http://dx.doi.org/10.1093/aje/kwp323

Chapman, B. P., van Wijngaarden, E., Seplaki, C. L., Talbot, N., Duberstein, P., \& Moynihan, J. (2011). Openness and Conscientiousness Predict 34-SSweek Patterns of Interleukin-6 in Older Persons. Brain, Behavior, and Immunity, 25, 667-673. http://dx.doi.org/10.1016/j.bbi.2011.01.003

Cheung, M. M., LeMay, K., Saini, B., \& Smith, L. (2014). Does Personality Influence How People with Asthma Manage Their Condition? Journal of Asthma, 14, 1-8.

Colbert, L. H., Visser, M., Simonsick, E. M., Tracy, R. P., Newman, A. B., Kritchevsky, S. B., Harris, T. B. et al. (2004). Physical Activity, Exercise, and Inflammatory Markers in Older Adults: Findings from the Health, Aging and Body Composition Study. Journal of the American Geriatrics Society, 52, 1098-1104. http://dx.doi.org/10.1111/j.1532-5415.2004.52307.x

Cole, S. W., Kemeny, M. E., Fahey, J. L., Zack, J. A., \& Naliboff, B. D. (2003). Psychological Risk Factors for HIV Pathogenesis: Mediation by the Autonomic Nervous System. Biological Psychiatry, 54, 1444-1456. http://dx.doi.org/10.1016/S0006-3223(02)01888-7

Costa Jr., P. T., \& McCrae, R. R. (1997). Stability and Change in Personality Assessment: The Revised NEO Personality Inventory in the Year 2000. Journal of Personality Assessment, 68, 86-94. http://dx.doi.org/10.1207/s15327752jpa6801_7

Craig, C. L., Marshall, A. L., Sjöström, M., Bauman, A. E., Booth, M. L., Ainsworth, B. E., Pratt, M., Ekelund, U., Yngve, 
A., Sallis, J. F., \& Oja, P. (2003). International Physical Activity Questionnaire: 12-Country Reliability and Validity. Medicine \& Science in Sports \& Exercise, 35, 1381-1395. PMID: 12900694.

de Jong, G. M., van Sonderen, E., \& Emmelkamp, P. M. G. (1999). A Comprehensive Model of Stress. Psychotherapy and Psychosomatics, 68, 290-298.

Dressendorfer, R. H., Petersen, S. R., Moss Lovshin, S. E., Hannon, J. L., Lee, S. F., \& Bell, G. J. (2002). Performance Enhancement with Maintenance of Resting Immune Status After Intensified Cycle Training. Clinical Journal of Sport Medicine, 12, 301-307.

Edwards, K. M., Burns, V. E., Ring, C., \& Carroll, D. (2006a). Individual Differences in the Interleukin-6 Response to Maximal and Submaximal Exercise Tasks. Journal of Sports Sciences, 24, 855-862. http://dx.doi.org/10.1080/02640410500245645

Edwards, K. M., Burns, V. E., Ring, C., \& Carroll, D. (2006b). Sex Differences in the Interleukin-6 Response to Acute Psychological Stress. Biological Psychology, 71, 236-239. http://dx.doi.org/10.1016/j.biopsycho.2005.06.006

Empana, J. P., Jouven, X., Canoui-Poitrine, F., Luc, G., Tafflet, M., Haas, B., Ducimetiere, P. et al. (2010). C-Reactive Protein, Interleukin 6, Fibrinogen and Risk of Sudden Death in European Middle-Aged Men: The PRIME Study. Arteriosclerosis, Thrombosis, and Vascular Biology, 30, 2047-2052. http://dx.doi.org/10.1161/ATVBAHA.110.208785

FitzGerald, L. (2011). Blunted Affect is Associated With Hypothalamic_Pituitary-Adrenal Axis (HPA) Hypoactivity and Elevated CSF-Interleukin-1 Beta (IL-1 $\beta$ ) in Response to Lumbar Puncture. Biological Research for Nursing, 13, $164-174$. http://dx.doi.org/10.1177/1099800410383558

Goodwin, R. D., \& Friedman, H. S. (2006). Health Status and the Five-Factor Personality Traits in a Nationally Representative Sample. Journal of Health Psychology, 11, 643-654. http://dx.doi.org/10.1177/1359105306066610

Halaris, A., Meresh, E., Fareed, J., Hoppenstead, D., Kimmons, S., \& Sinacore, J. (2012). 1. Interleukin-6 as a Biomarker in Major Depressive Disorder. Brain, Behavior, and Immunity, 26, S1. http://dx.doi.org/10.1016/j.bbi.2012.07.025

Jankord, R., \& Jemiolo, B. (2004). Influence of Physical Activity on Serum IL-6 and IL-10 Levels in Healthy Older Men. Medicine \& Science in Sports \& Exercise, 36, 960-964.

Jonassaint, C. R., Boyle, S. H., Williams, R. B., Mark, D. B., Siegler, I. C., \& Barefoot, J. C. (2007). Facets of Openness Predict Mortality in Patients With Cardiac Disease. Psychosomatic Medicine, 69, 319-322. http://dx.doi.org/10.1097/PSY.0b013e318052e27d

Jonassaint, C. R., Boyle, S. H., Kuhn, C. M., Siegler, I. C., Copeland, W. E., \& Williams, R. (2010). Personality and Inflammation: The Protective Effect of Openness to Experience. Ethnicity Disease, 20, 11-14.

Kim, Y.-W., West, X., \& Byzova, T. (2013). Inflammation and Oxidative Stress in Angiogenesis and Vascular Disease. Journal of Molecular Medicine, 91, 323-328. http://dx.doi.org/10.1007/s00109-013-1007-3

Lira, F. S., Rosa, J. C., Pimentel, G. D., Tarini, V. A., Arida, R. M., Faloppa, F., Santos, R. V. et al. (2010). Inflammation and Adipose Tissue: Effects of Progressive Load Training in Rats. Lipids in Health and Disease, 9, 109. http://dx.doi.org/10.1186/1476-511X-9-109

Ma, L. J., Guzmán, E. A., DeGuzman, A., Muller, H. K., Walker, A. M., \& Owen, L. B. (2007). Local Cytokine Levels Associated with Delayed-Type Hypersensitivity Responses: Modulation by Gender, Ovariectomy, and Estrogen Replacement. Journal of Endocrinology, 193, 291-297. http://dx.doi.org/10.1677/joe-06-0024

Mõttus, R., Luciano, M., Starr, J. M., Pollard, M. C., \& Deary, I. J. (2013). Personality Traits and Inflammation in Men and Women in Their Early 70s: The Lothian Birth Cohort 1936 Study of Healthy Aging. Psychosomatic Medicine, 75, 11-19. http://dx.doi.org/10.1097/PSY.0b013e31827576cc

Nimmo, M. A., Leggate, M., Viana, J. L., \& King, J. A. (2013). The Effect of Physical Activity on Mediators of Inflammation. Diabetes, Obesity and Metabolism, 15, 51-60. http://dx.doi.org/10.1111/dom.12156

Putnam, K., Chrousos, G. P., Nieman, L. K., \& Rubinow, D. R. (2005). Sex-Related Differences in Stimulated Hypothalamic-Pituitary-Adrenal Axis during Induced Gonadal Suppression. Journal of Clinical Endocrinology \& Metabolism, 90, 4224-4231. http://dx.doi.org/10.1210/jc.2004-2525

Roberts, B. W., Caspi, A., \& Moffitt, T. E. (2001). The Kids Are Alright: Growth and Stability in Personality Development from Adolescence to Adulthood. Journal of Personality and Social Psychology, 81, 670-683.

http://dx.doi.org/10.1037/0022-3514.81.4.670

Segerstrom, S. C., Taylor, S. E., Kemeny, M. E., \& Fahey, J. L. (1998). Optimism Is Associated with Mood, Coping, and Immune Change in Response to Stress. Journal of Personality and Social Psychology, 74, 1646-1655. http://dx.doi.org/10.1037/0022-3514.74.6.1646

Steptoe, A., \& Molloy, G. J. (2007). Personality and Heart Disease. Heart, 93, 783-784. http://dx.doi.org/10.1136/hrt.2006.109355 
Suls, J., Krantz, D. S., \& Williams, G. C. (2013). Three Strategies for Bridging Different Levels of Analysis and Embracing the Biopsychosocial Model. Health Psychology, 32, 597-601. http://dx.doi.org/10.1037/a0031197

Sutin, A. R., Terracciano, A., Deiana, B., Naitza, S., Ferrucci, L., Uda, M., Costa, P. T. J. et al. (2010). High Neuroticism and low Conscientiousness are associated with interleukin-6. Psychological Medicine, 40, 1485-1493. http://dx.doi.org/10.1017/S0033291709992029

Temoshok, L. R., Wald, R. L., Synowski, S., \& Garzino-Demo, A. (2008). Coping as a Multisystem Construct Associated With Pathways Mediating HIV-Relevant Immune Function and Disease Progression. Psychosomatic Medicine, 70, 555-561. http://dx.doi.org/10.1097/PSY.0b013e318177354f

Terracciano, A., Lockenhoff, C., Crum, R., Bienvenu, O. J., \& Costa, P. (2008). Five-Factor Model Personality Profiles of Drug Users. BMC Psychiatry, 8, 22.

Turiano, N. A., Mroczek, D. K., Moynihan, J., \& Chapman, B. P. (2013). Big 5 Personality Traits and Interleukin-6: Evidence for "Healthy Neuroticism” in a US Population Sample. Brain, Behavior, and Immunity, 28, 83-89. http://dx.doi.org/10.1016/j.bbi.2012.10.020

Widiger, T. A., \& Costa, P. T. (2012). Integrating Normal and Abnormal Personality Structure: The Five-Factor Model. Journal of Personality, 80, 1471-1506. http://dx.doi.org/10.1111/j.1467-6494.2012.00776.x 
Scientific Research Publishing (SCIRP) is one of the largest Open Access journal publishers. It is currently publishing more than 200 open access, online, peer-reviewed journals covering a wide range of academic disciplines. SCIRP serves the worldwide academic communities and contributes to the progress and application of science with its publication.

Other selected journals from SCIRP are listed as below. Submit your manuscript to us via either submit@scirp.org or Online Submission Portal.
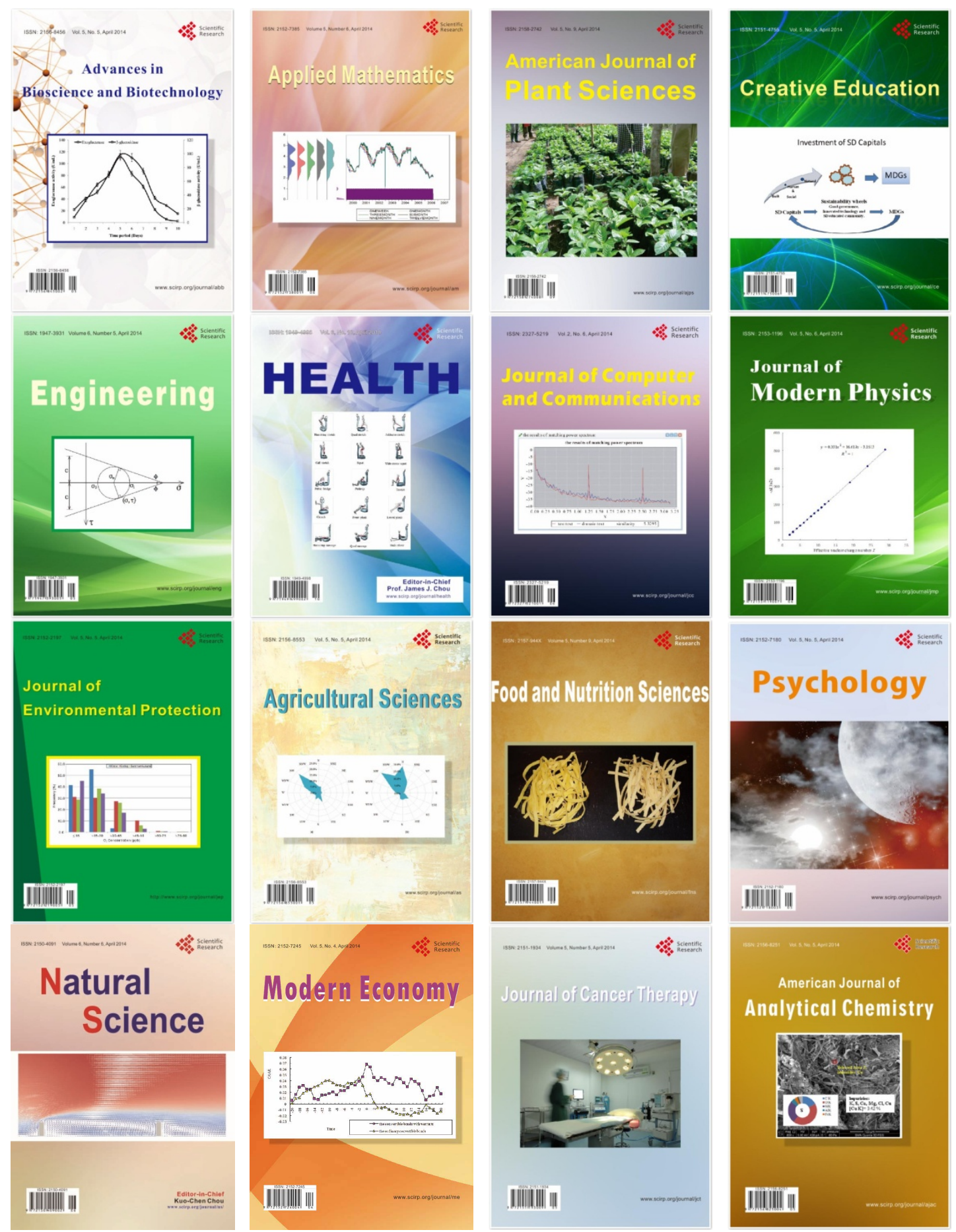